\title{
Budidaya Terpadu Ikan dan Sayuran melalui Metode Akuaponik Di Desa Serut Kecamatan Panti Kabupaten Jember
}

\author{
Parawita Dewanti ${ }^{1}$, Didik Pudji Restanto², Sigit Soepardjono ${ }^{3}$, Bambang \\ Sugiharto ${ }^{4}$ \\ Universitas Jember \\ parawita@yahoo.co.id
}

\begin{abstract}
Abstrak
Sosialisasi dan praktek usaha hidroponik sudah dilakukan melalui posdaya yang dibentuk oleh Lembaga Pengabdian Universitas Jember di Dusun Karang Anom desa Serut Kecamatan Panti Kabupaten Jember. Desa Serut dipilih sebagai target pada program pengembangan desa mitra karena mempunyai potensi tinggi untuk pengembangan sayuran hidroponik ditinjau dari lokasi, kepedulian dan kemandirian masyarakatnya serta mempunyai jiwa kewirausahaan. Disisi lain, hasil observasi ditemukan pula sebagian penduduk di Dusun Karang Anom desa Serut Kecamatan Panti memiliki usaha budidaya ikan yang sudah berjalan beberapa tahun terakhir. Upaya Budidaya terpadu sayuran dan ikan melalui metode Akuaponik diharapkan menghasilkan 2 produk sekaligus dalam satu kali proses produksi, sehingga akan diperoleh produk yang bermanfaat bagi masyarakat setempat dan masyarakat secara luas untuk penenuhan pangan dan gizi keluarga.Target yang diharapkan adalah agar anggota kelompok mitra memiliki kemampuan dan ketrampilan dalam mengelola budidaya terpadu ikan dan sayuran dalam satu kali proses produksi. Oleh karena itu diperlukan sarana dan prasarana yang memadai sehingga kelompok mitra dapat memanfaatkan teknologi akuaponik. Hasil kegiatan menunjukkan bahwa terjadi respon positif dari anggota kelompok mitra yang ditunjukkan oleh antusias peserta dalam mengikuti serangkaian pelatihan dari awal sampai selesai. Telah diperoleh hasil produk dalam satu kali produksi akuaponik per bulan akan menghasilkan ikan lele sebanyak $50 \mathrm{~kg}$ dan sayuran $40 \mathrm{~kg}$. Untuk 3 unit kolam ikan akan dihasilkan ikan lele $150 \mathrm{~kg}$ dan $120 \mathrm{~kg}$ sayuran dalam waktu 3 bulan.
\end{abstract}

Kata Kunci: Akuaponik, Ikan lele, Sayuran, Hidroponik

\begin{abstract}
Socialization and hydroponic business practices have been carried out through a Posdaya established by the Jember University Service Institute in Karang Anom Hamlet in Serut village, Panti District, Jember Regency. Serut village was chosen as a target in the partner village development program because it has high potential for the development of hydroponic vegetables in terms of location, community awareness and independence and has an entrepreneurial spirit. On the other hand, the results of observations also found that some residents in Karang Anom Hamlet in Serut Village, Panti District have a fish farming business that has been running for the past few years. Efforts of integrated cultivation of vegetables and fish through the Aquaponics method are expected to produce 2 products at once in a one-time production process, so that products that will benefit the local community and the community at large to meet family food and nutrition are expected. and skills in managing integrated fish and vegetable cultivation in one production process. Therefore, adequate facilities and infrastructure are needed so
\end{abstract}


that the partner groups can utilize aquaponics technology. The results of the activity showed that there was a positive response from the members of the partner group which was shown by the enthusiasm of the participants in participating in a series of training from start to finish. The product has been obtained in one aquaponic production per month will produce $50 \mathrm{~kg}$ of catfish and $40 \mathrm{~kg}$ of vegetables. For 3 units of fish ponds, 150 $\mathrm{kg}$ of catfish and $120 \mathrm{~kg}$ of vegetables will be produced within 3 months.

Keywords: Aquaponics, Catfish, Vegetables, Hydroponics

\section{PENDAHULUAN}

Kecamatan Panti Kabupaten Jember mempunyai beberapa desa yaitu Glagahwero, Kemuning Lor, Panti, Pakis, Kemiri dan Serut. Desa Serut merupakan salah satu desa yang memiliki enam dusun yaitu Dusun Krajan, Mencek, Badean Wetan, Karang Anom, Badean Kulon, dan Kasian. Potensi desa Serut masih belum dikembangkan secara efisien seperti lahan yang belum termanfaatkan secara optimal, tenaga kerja potensial dan lokasi yang strategis. Oleh karena itu, diperlukan pengembangan dan inovasi dalam pemanfaatan potensi desa untuk meningkatkan nilai tambah.

Beberapa desa di kecamatan Panti tersebut telah memiliki pos daya seperti di dusun Karang Anom dan dusun Badean Wetan. Kedua pos daya tersebut bertempat di salah satu rumah warga yakni Bapak Bambang dan Bapak Ilyas selaku ketua pelaksana pos daya. Pos daya di dusun Badean Wetan dibentuk berdasarkan inisiatif mahasiswa KKN (Kuliah Kerja Nyata) pada dua tahun 2016. Pada awal berdirinya pos daya, masyarakat diberi pelatihan tentang teknik budidaya modern dengan sistem hidroponik dan pengolahan produknya. Namun setelah mahasiswa KKN kembali ke Universitas Jember kegiatan tidak dilanjutkan. Oleh karena itu, masyarakat kembali menganggur dan pos daya menjadi vakum, selain itu pengurus dari pos daya fokus dengan pekerjaan lain dan akhirnya menjadi terbengkalai.

Kondisi dusun di Desa Serut memiliki potensi dan permasalahan yang berbeda-beda, padahal potensi pendukung yang ada cukup menjanjikan. Seiring berkembangnya teknologi yang tidak dapat dihindari, teknologi pertanian juga mengalami perkembangan pesat. Hingga pada abad 20 ini terdapat beberapa macam sistem budidaya pertanian yang berkembang pada kehidupan masyarakat. Sistem budidaya pertanian yang ada pada masyarakat saat ini sangat beragam dari pertanian konvensional, organik, hidroponik, vertikulultur dan Akuaponik.

Desa Serut dipilih sebagai target pada program pengembangan desa mitra karena mempunyai potensi tinggi untuk pengembangan sayuran hidroponik ditinjau dari lokasi, kepedulian dan kemandirian masyarakatnya serta mempunyai jiwa kewirausahaan. Disisi lain, hasil observasi ditemukan pula sebagian penduduk di Dusun Karang Anom desa Serut Kecamatan Panti memiliki usaha budidaya ikan yang sudah berjalan beberapa tahun terakhir. Beberapa 
pengabdian tentang hidroponik telah dilakukan di desa ini, baik dengan dana mandiri maupun melalui pendanaan dengan skim unggulan Perguruan Tinggi, namun masih diperlukan upaya pengembangan agar hasilnya lebih maksimal dan dapat berpotensi untuk dikembangkan menjadi desa sentra sayuran dan ikan air tawar.

Program sentra sayuran dan ikan air tawar sebaiknya didukung oleh akademisi perguruan tinggi dalam menyampaikan materi dilapangan. Program kegiatan ini dapat dimulai dari pendampingan di sekolah agar bermanfaat bagi siswa dalam memahami tentang cinta bangsa, negara dan tanah air. Program ini dapat dikembangkan menjadi Program wisata Pendidikan sebagai pendamping program pembelajaran dalam kelas, sehingga akan efektif untuk meningkatkan pola pembelajaran dan sosialisasi para siswa.

Program ini akan berdampak luas bagi pengembangan ekonomi di daerah karena dapat mendukung pergerakan ekonomi rakyat. Prospek sentra sayuran dan ikan air tawar berbasis pelajar sekolah di Indonesia diprediksikan makin cerah. Jika jumlah pelajar di tingkat Sekolah Dasar (SD), Sekolah Menengah Pertama (SMP) sampai Sekolah Menengah Atas (SMA) di daerah Jember semakin banyak seperti tercatat di Badan Pusat Statistik (BPS), maka potensi sentra sayuran dan ikan air tawar di Jember akan semakin cerah. Dengan pergerakan pelajar ke kecamatan Panti Kabupaten Jember, bisa dibayangkan berapa nilai rupiah yang bisa berputar karena dibelanjakan oleh masyarakat.

Dari kegiatan ini diharapkan banyak bermunculan ragam obyek wisata yang bisa dimanfaatkan oleh penjual jasa pariwisata, sehingga dapat mendukung terciptanya lapangan kerja bagi masyarakat. Dengan program Akuaponik serta pengembangannya dibidang yang lain dapat memberikan lapangan kerja bagi warga setempat, sehingga apabila program sentra sayuran dan ikan air tawar tersebut berkembang maka akan dapat dimanfaatkan oleh pemerintah dan masyarakat daerah itu. Melalui promosi yang berkesinambungan akan menjadi salah satu solusi untuk meningkatkan kesejahteraan masyarakat.

\section{A. Target dan Luaran}

Target dan luaran yang dicapai adalah produksi ikan dan sayuran dalam satu periode secara bersamaan. Produk ikan dan sayuran dikembangkan sebagai upaya menjadi desa sentra sayuran hidroponik dan ikan air tawar. Inovasi metode akuaponik akan memiliki nilai tambah, tidak sekedar budidaya sayuran dan ikan, namun juga pemenuhan pangan dan gizi di desa Serut. Untuk memudahkan pelaksanaan dilakukan pembangunan kolam ikan dan instalasi hodroponik. Selain itu juga menghasilkan paket budidaya ikan dan sayuran melalui metode akuaponik. 


\section{METODE PELAKSANAAN}

Pelaksanaan Pengabdian secara rinci dapat dilihat pada tahapan berikut:

\section{A. Sosialisasi}

Melakuan sosialisasi kepada beberapa kepala keluarga terutama tokoh masyarakat dengan cara melakukan pertemuan yang dihadiri oleh dosen, perwakilan masyarakat, mahasiswa dan tokoh masyarakat. Sosialisasi bertujuan untuk memperoleh masukan untuk penyempurnaan pogram ini agar dapat berjalan dengan baik dan dapat diterima oleh masyarakat setempat.

Komunitas akan dibentuk dengan melibatkan pos daya, karang taruna dan PKK sebagai pengurus dan anggota. Pos Daya dilatih untuk menjadi tenaga yang khusus memperdalam mengenai pelatihan tehnik budidaya hidroponik. Karang taruna disiapkan menjadi produsen produk sayuran hidroponik dan PKK disiapkan menjadi pengelola pasca panen dan pemasaran produk. Namun ke 3 komponen komunitas tersebut dilatih secara bersama-sama sehingga menguasai teknik budidaya ikan air tawar, teknik budidaya sayuran hidroponik, teknik panen, penaganan pasca panen dan pemasaran.

\section{B. Pelatihan Budidaya ikan dan sayuran hidroponik dengan metode akuaponik}

Pelatihan adalah metode percontohan dalam pembuatan system budidaya sayuran secara Akuaponik di pekarangan rumah masyarakat. Pelatihan ini harus dihadiri masing-masing anggota mitra atau perwakilan untuk mulai melakukan persipan pelaksanaan program. Pembuatan instalasi Akuaponik dan sebar benih mulai dilakukan saat pelatihan agar meringankan beban tugas saat tahap pelaksanaan program. Hal ini untuk membuat peserta pelatihan tidak merasa bosan dalam mengikuti serangkaian kegiatan program. Pelatihan dilakukan secara terpusat di pekarangan rumah kepala dusun agar memudahkan warga dalam melakukan distribusi perlengkapan dalam tahap pelaksanaan. Hal-hal yang perlu dipersiapkan antara lain :

a. Kolam yang dipasang instalasi hidroponik menjadi satu set instalasi Akuaponik.

b. Benih untuk disebar sebagai tahap awal budidaya Akuaponik.

c. Handout mengenai gambaran skema Akuaponik. Handout dibuat banyak berupa gambar untuk memudahkan masyarakat memahami metode yang akan dibuat, selain itu untuk memudahkan peserta pelatihan yang memiliki kekurangan dalam membaca keaksaraan. 
C. Praktek budidaya teknologi Akuaponik

\section{Penyiapan Instalasi Akuaponik}

Instalasi dibuat dengan menggunakan bahan pipa PVC/paralon yang diberi lubang tanam untuk menempatkan pot-pot kecil (netpot) berisi bibit tanaman. Pipa PVC yang telah diberi lubang kemudian disambungkan dengan sebuah pompa untuk mengalirkan nutrisi dari air kolam ikan. Air yang mengandung nutrisi berasal dari limbah kotoran ikan. Pemberian nutrisi dilakukan dalam durasi waktu tertentu mengikuti sistem hidroponik NFT (Nutrient Film Technique) dan Substrat. Substrat/Media ditempatkan di dalam polybag, bambu panjang berlubang, pot plastic, pot tanah dan wadah lain sesuai dengan ketersediaan dan nilai ekonomi dari wadah media.

\section{Pembuatan Kolam Ikan}

Kolam ikan dibuat dengan ukuran $2 \mathrm{~m}$ x $3 \mathrm{~m}$ x $1 \mathrm{~m}$ sebanyak 3 unit. Dinding kolam berasal dari batako dan semen yang dihubungkan dengan kolam pembuangan kotoran ikan sebagai sumber nutrisi bagi sayuran hidroponik. Kolam ikan dilengkapi dengan pengatur oksigen untuk ikan dan pompa untuk mengalirkan nutrisi pada instalasi Akuaponik.

\section{Pembibitan dan Penebaran Ikan Dalam Kolam}

Proses Pembibitan dilakukan dengan cara menyemaikan benih tanaman pada rockwool. Rockwool dipotong dadu $2 \mathrm{~cm}$ x $2 \mathrm{~cm}$ kemudian disiram air sampai lembab. Rockwool diletakkan pada nampan dan digunakan untuk menanam benih sayuran. Benih yang telah berkecambah disiram dengan larutan nutrisi dengan konsentrasi 300-500 ppm (konsentrasi disesuaikan dengan dengan kebutuhan setiap jenis sayuran). Setelah muncul 3-4 helai daun bibit dapat dipindah tanam pada netpot. Benih ikan berukuran $5 \mathrm{~cm}$ hingga $7 \mathrm{~cm}$ ditebar pada kolam akuaponik. Populasi ikan lele 1500 ekor per kolam. Selain itu jumlah populasi ikan dan umur ikan harus disesuaikan dengan dengan jenis sayuran yang akan ditanam.

\section{Pemindahan Bibit dan Penanaman}

Tahap pemindahan bibit sayuran dilakukan ketika bibit telah berumur 10 hari masa semai dan memiliki 3-4 daun. Memindahkan bibit beserta rockwool ke dalam netpot beserta sumbu berupa kain flanel berukuran 3 x $20 \mathrm{~cm}$. Kemudian 
menempatkan pada perangkat Akuaponik yang telah teraliri larutan nutrisi yang berasal dari kolam ikan.

\section{Perawatan dan Pemeliharaan}

Proses perawatan yang dilakukan selama proses pembudidayaan tersebut meliputi penyulaman, pengendalian hama dan penyakit tanaman, pemberian pakan ikan secara rutin, penggantian air kolam, serta pengecekan kondisi air kolam dengan $\mathrm{pH}$ meter dan TDS meter. Penyulaman dilakukan pada tanaman yang mati atau tumbuh abnormal. Pemberian pakan disesuaikan dengan populasi ikan pada kolam, hal ini dikarenakan jumlah pakan yang diberikan juga berpengaruh terhadap kotoran ikan yang dihasilkan yang selanjutnya dimanfaatkan sebagai nutrisi tanaman. Pengendalian hama dan penyakit dilakukan secara manual tanpa menggunakan pestisida agar tanaman dan ikan tidak terkontaminasi dengan bahan kimia berbahaya atau dapat pula dengan menggunakan pestisida nabati sebagai tindakan preventif untuk mencegah adanya hama dan penyakit namun tetap aman bagi budidaya ikan.

\section{HASIL DAN PEMBAHASAN}

Kegiatan pengabdian PPU tentang budidaya terpadu ikan dan sayuran melalui metode akuaponik di Desa Serut Kecamatan Panti Kabupaten Jember dilakukan dengan fokus sesuai dengan permasalahan yang ada. Kegiatan tersebut adalah:

\section{A. Koordinasi Kegiatan dan sosialisasi}

Kegiatan pengabdian masyarakat dilakukan dengan dasar kerjasama dan kekeluargaan. Pada kondisi lapang membangun sebuah komunikasi yang baik dengan masarakat sangat dibutuhkan untuk membangun sebuah kepercaaan sehingga hubungan kemitraan dapat berjalan dengan baik. Perjanjian kemitraan dilakukan dengan kelompok masyarakat yakni kelompok PKK, Posdaya, dan Karang Taruna diwilayah setempat.

Survey lokasi demoplot dilakukan di lahan milik mitra yakni bapak Ilyas. Demoplot dibangun untuk memberikan edukasi sebagai percontohan bagi masyarakat setempat. Lokasi yang akan digunakan sebagai pembuatan instalasi aquaponik harus sesuai pula untuk budidaya ikan ditinjau dari ketinggian tempat dan suhu wilayahnya. Lokasi mitra memiliki kriteria yang tepat digunakan sebagai lokasi demoplot. 


\section{B. Pembangunan Kolam ikan dan instalasi Hidroponik}

Proses Pengerjaan kolam Ikan dilakukan oleh tenaga ahli dan warga setempat. Pengerjaan kolam dilakukan secara bergotong royong untuk menjaga hubungan baik sehingga diharapkan hasil yang didapatkan nanti tidak dianggap sebagai milik salah satu pihak akan tetapi dapat menjadi sebuah usaha bersama untuk meningkatkan taraf hidup masyarakat. Pembuatan Kolam dilakukan sebelum pelatihan agar mitra dapat melihat contoh produk sehingga materi yang disampaikan nantinya memberikan dampak yang positif dan lebih mudah diterima oleh masyarakat. Kendala pengerjaan berupa cuaca yang tidak bersahabat dimana sering terjadi hujan lebat sehingga mengakibatkan pembangunan sempat terhenti untuk beberapa waktu. Kolam yang telah siap sebelum diisi ikan harus diisi air kurang lebih 1 minggu untuk menghilangkan bau semen sekaligus mengecek kondisi kolam. Kolam dibangun setinggi 1 meter dengan ukuran 3x2 sebanyak 3 kolam berdekatan sebagai kolam pembibitan dan pembesaran.

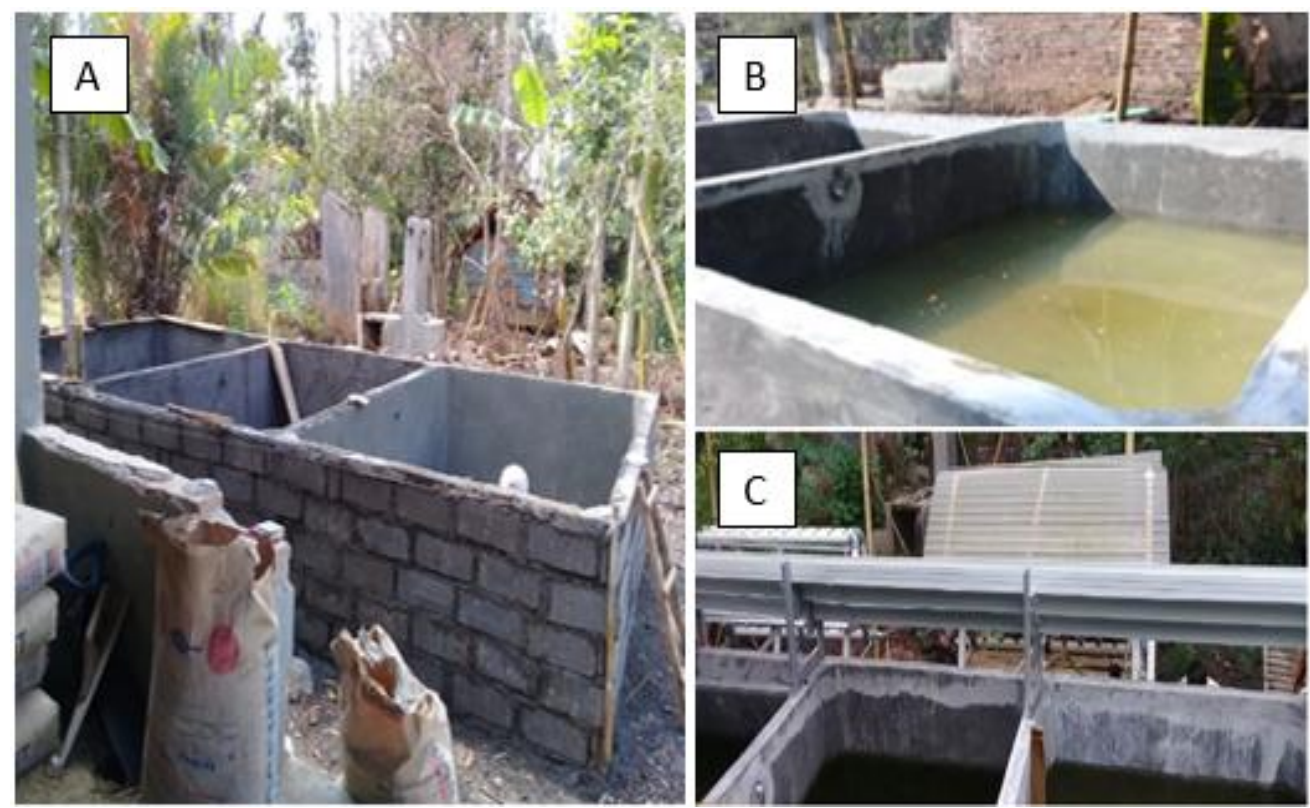

Gambar 1. Kolam Ikan dan Istalasi Hidroponik, A) Pembuatan Kolam Ikan,

B) kolam Ikan Air Tawar, C) Instalasi Aquaponik.

\section{Pelatihan}

Kegiatan pelatihan ditujukan pada anggota mitra agar mengetahui maksud dan tujuan program ini. Kegiatan pelatihan dilakukan dengan cara penyampaian materi oleh Tim Pelaksana sebagai narasumber. Adapun naman narasumber dan materi penyuluhan terdapat pada tabel 1 . Selain penyampaian materi peserta juga diberi kesempatan untuk tanya jawab apabila ada meteri yang belum jelas. 
TABEL I. NARASUMBER dan MATERI PELATIHAN

\begin{tabular}{|l|l|l|}
\hline No. & \multicolumn{1}{|c|}{ Narasumber } & \multicolumn{1}{c|}{ Materi Pelatihan } \\
\hline 1. & $\begin{array}{l}\text { Dr. Ir. Parawita } \\
\text { Dewanti, MP }\end{array}$ & $\begin{array}{l}\text { Akuaponik sebagai alternatif untuk } \\
\text { penyediaan pangan dan peningkatan gizi } \\
\text { keluarga }\end{array}$ \\
\hline 2. & $\begin{array}{l}\text { Dr. Ir. Didik Pudji } \\
\text { Restanto, MS }\end{array}$ & Budidaya ikan air tawar \\
\hline 3. & $\begin{array}{l}\text { Dr. Ir. Sigit } \\
\text { Soepardjono, MS }\end{array}$ & $\begin{array}{l}\text { Budidaya Hidroponik dengan sistem } \\
\text { vertikultur }\end{array}$ \\
\hline 4. & $\begin{array}{l}\text { Prof. Bambang } \\
\text { Sugiharto }\end{array}$ & Nutrisi tanaman hidroponik \\
\hline
\end{tabular}

\section{Praktek}

Pembibitan sayuran dilakukan pada media rockwool. Jenis sayuran yang dibibitkan adalah jenis sayuran daun seperti slada, kangkung dan sawi. Pembibitan sawi dilakukan dengan menanam satu benih sawi atau slada dalam setiap potong rockwool berukuran 2 x $2 \mathrm{~cm}$, berbetuk kubus. Sedangkan untuk jenis sayuran berkanopi sempit seperti kangkung ditanam 7-10 bibit dalam 1 netpot. Rockwool yang berisi benih yang sudah berkecambah diletakkan di tempat yang terkena sinar matahari. Bibit siap pindah tanam umur 10-12 hari. Hasil Pembibitan sayuran dapat dilihat pada gambar 4 dan pemindahan bibit pada netpot dapat dilihat pada gambar 5 .

\section{E. Demplot}

Demplot dilakukan menggunakan metode akuaponik yaitu membudidayakan ikan air tawar dan sayuran daun dalam satu proses produksi. Ikan air tawar yang digunakan adalah ikan lele sedangkan sayuran yang dibudidayakan adalah kangkung dan sawi. Nutrisi untuk budidaya sayuran berasal dari limbah kotoran ikan lele, nutrisi ini sudah mengandung unsur makro dan mikro sesuai dengan kebutuhan tanaman.

Ikan lele dibudidayakan dalam 3 kolam dengan ukuran dan umur lele yang berbeda. Kolam 1: lele ukuran $9 \mathrm{~cm}$, kolam 2: lele ukuran $12 \mathrm{~cm}$ dan kolam 3: ukuran $17 \mathrm{~cm}$. Ikan lele dapat dipanen setiap bulan, panen pertama dilakukan pada kolam ke 3 dengan ukuran lele $20-25 \mathrm{~cm}$ atau $1 \mathrm{~kg}$ berisi 15 ikan. Berarti dalam satu kolam dapat dipanen sekitar $50 \mathrm{~kg}$ ikan.

Sayuran sawi atau kangkung dapat dipanen setiap bulan dengan produksi $40 \mathrm{~kg}$ per bulan. Yang perlu diperhatikan adalah pengaturan dalam pembuatan 
bibit, karena sebelum tanamn bibit harus dipersiapkan 10-12 hari sebelumnya. Hasil budidaya sayur hidroponik dapat dilihat pada gambar 6 .

Panen pertama dikonsumsi secara bersama oleh anggota mitra, hal ini untuk meningkatkan semangat anggota bahwa anggota sudah bisa melakukan budidaya akuaponik. Selanjutnya budidaya akuaponik akan dilanjutkan secara mandiri oleh anggota mitra baik secara kelompok maupun mandiri.

\section{F. Pendampingan}

Pendampingan bertujuan untuk memonitor penerapan iptek oleh kepompok mitra. Pelaksanaan kegiatan kegiatan PPU mendapat respon positif dari anggota mitra desa Serut kecamatan Panti Kabupaten Jember. Hal ini dapat dilihat dari keaktifan anggota dalam kegiatan ini (Gambar 7) bahkan banyak yang berinovasi menggunakan limbah botol dan gelas untuk berbudidaya hidroponik di lahan pekarangan masing-masing anggota (Gambar 8). Respon yang lain juga ditunjukkan dengan kesediaan mereka untuk memberikan lahan untuk demplot. Anggota mitra sangat antusias dalam menerima dan menerapkan teknologi yang diberikan, khususnya limbah kotoran lele untuk budidaya hidroponik sayuran yang merupakan inovasi baru bagi mereka.
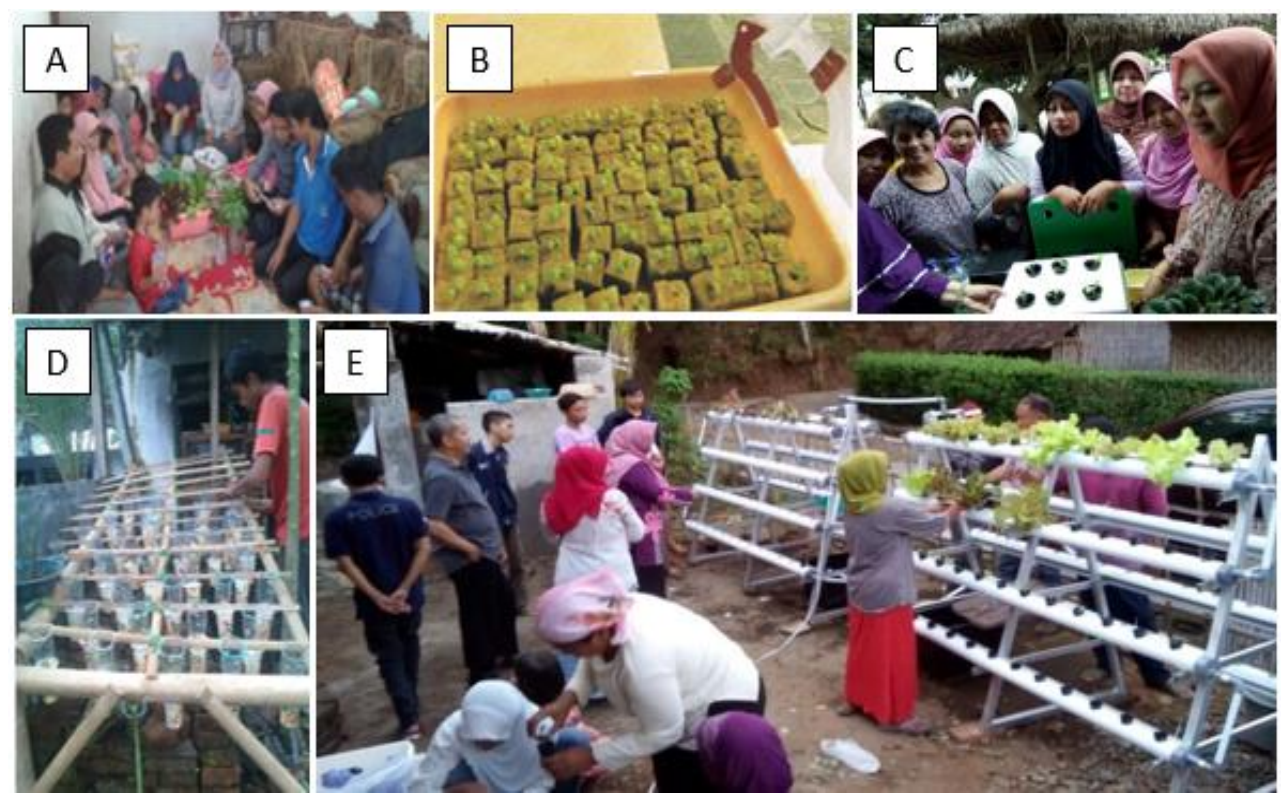

Gambar 2. Pelatihan dan Pengawasan, A) Pelatihan Budidaya Hidroponik, B) Penyemaian Benih Sayur, C) Praktek Memidah Bibit sayuran Dalam Net Pot,

D) Budidaya hidroponik dengan menggunakan limbah botol dan gelas, E)

Pendampingan dalam menanam sayuran hidroponik. 


\section{KESIMPULAN}

Persiapan pelaksanaan pengabdian meliputi kordinasi kegiatan, pembangunan instalasi hidroponik dan kolam ikan, pelatihan, praktek, demplot dan pendampingan sudah dilaksanakan sesuai dengan target yang ingin dicapai. Pelaksanaan Kegiatan Pengabdian PPU ini mendapat respon positif dari anggota kelompok mitra, hal ini ditunjukkan dari antusiasme peserta dalam mengikuti pelatihan dari awal sampai akhir serta secara mandiri menerapkan hasil pelatihan yang diperoleh dengan budidaya ikan dan sayuran melalui metode akuaponik. Hasil budidaya terpadu melalui metode akuaponik diperoleh bahwa dalam satu kali produksi akuaponik per bulan akan menghasilkan ikan lele sebanyak $50 \mathrm{~kg}$ dan sayuran $40 \mathrm{~kg}$, sehingga dengan 3 unit kolam ikan, maka akan dihasilkan ikan lele $150 \mathrm{~kg}$ dan $120 \mathrm{~kg}$ sayuran dalam waktu 3 bulan.

\section{UCAPAN TERIMA KASIH}

Ucapan terimakasih kepada Hibah Internal Pengabdian Kepada Masyarakat Universitas Jember Tahun Anggaran 2018 yang telah mendanai melalui Program Pengabdian Unggulan (PPU) dengan SK Rektor 12435/UN25/LT/2018.

\section{DAFTAR PUSTAKA}

Dewanti, P., S. Kamalia, K.A. Wijaya dan S. Hartatik. "Utilization of yard for vegetable hydroponics in Serut Village, Panti Sub-District, Jember District" (2018) 03:01 Asian Journal Of Innovation and Entrepreneurship.

Effendi, H., B. A. Utomo, G. M. Darmawangsa, dan R. E. Karo-Karo. "Fitoremediasi Limbah Budidaya Ikan Lele (Clarias sp.) dengan Kangkung (Ipomoea Aquatica) Dan Pakcoy (Brassica rapa chinensis) dalam Sistem Resirkulasi" (2015) 9:2 Ecolab 47-104.

Graber A and R Junge. "Aquaponic Systems: Nutrient Recycling from WasteWater by Vegetable Production.Institute for Natural Resource Sciences Gruental. Waedenswil, Switzerland" (2009) 246 Desalination 147 156.

Lingga, P. HIDROPONIK: Bercocok Tanam Tanpa Tanah (Jakarta: Penebar Swadaya. 2005).

Nugroho, R.A., L.T. Pambudi, Diana C., dan A.H.C. Haditomo. "Aplikasi Teknologi Aquaponic padaBudidaa Ikan Air Tawar untuk Optimalisasi Kapasitas Produksi” (2012) 08:1 Jurnal Saintek Perikanan 46-50. 
Putra, Iskandar dan N. Ayu Pamungkas. Pemeliharaan Ikan Selais (Ompok sp) dengan Resirkulasi Sistem Akuaponik" (2011) 16:1 Perikanan dan Kelautan 125-131.

Rokhmah, N. A., C. S. Ammatillah, dan Y. Sastro. "Vertiminaponik, Mini Akuaponik untuk Lahan Sempit di Perkotaan” (2014) 4:2 Buletin Pertanian Perkotaan 14-22.

Saptarini, P. "Efektivitas Teknologi Akuaponik dengan Kangkung Darat (Ipomoea reptans) terhadap Penurunan Amonia pada Pembesaran Ikan Mas. [Skripsi]" (2010) 69 Departemen MSP FPIK IPB. Bogor.

Setijaningsih, L dan C. Umar. "Pengaruh Lama Retensi Air terhadap Pertumbuhan Ikan Nila (Oreochromis niloticus) pada Budidaya Sistem Akuaponik dengan Tanaman Kangkung" (2015) 14:3 Berita Biologi 267-275.

Sungkar, M. Akuartiaponik Ala Mark Sungkar (Jakarta: Agromedia Pustaka, 2015).

Surnar, S. R., Sharma, O. P., and Saini, V. P. Aquaponics: Innovative farming" (2015) 2:4 International Journal of Fisheries and Aquatic Studies 261-263. 